training placement, while RCPCH data (2007) suggests that only $50-60 \%$ of qualified GPs have had any formal paediatric training. The educational model of Learning Together clinics was therefore developed to address these challenges and improve training in community child health for GP and Paediatric trainees.

Intervention "Learning Together clinics": child health clinics within a primary care setting, were launched in 40 sites across London. Each clinic site provided joint training with Paediatric and GP registrars seeing children together.

Patients were discussed after the clinics in multidisciplinary practice team meetings to allow for clinical continuity and cascading learning to other health professionals.

Evaluation A combination of methods were used including:

Pre and post intervention registrar surveys $(n=300)$

Case $\log$ analysis $(\mathrm{n}=683)$

Surveys with families after clinics $(\mathrm{n}=351)$

Follow up phone surveys with families $(\mathrm{n}=125)$

Registrar focus groups $(\mathrm{n}=19)$

Audit of practice notes $(n=22)$

Results Over the 6 month pilot funded by HECL through UCLP, 848 children were seen in 145 LT clinics

37 Paediatric Registrars and 40 GP Registrars made up 44 pairs in 40 GP practices

99\% of 351 parent forms said they had a good experience of care.

$87 \%$ of parents reported increased confidence to manage their child's health.

Trainees reported a good learning experience and change in behaviour as a result of the clinics

Trainees reported that $55 \%$ of Learning Together appointments resulted in an avoided referral or A\&E visit

A notes audit of 22 practices before, during and after the clinics suggests that there is better adherence to National Guidance for common childhood conditions as a result of the clinics.

Implications Learning together clinics are a valuable educational training model: they are feasible and economically viable.

A further study is being led by South London to broaden the impact of the programme and further evaluate clinical outcomes

\section{G176 A NATIONAL UNDERGRADUATE CHILD HEALTH CURRICULUM: WHAT ARE THE CORE COMPONENTS?}

${ }^{1} \mathrm{HC}$ Jacob, ${ }^{1,2} \mathrm{CR}$ Fertleman. 'Institute of Child Health, University College London, London, UK; ${ }^{2}$ Department of Paediatrics, Whittington Hospital, London, UK

\subsection{6/archdischild-2015-308599.171}

Aims There is a pressing need to improve health outcomes for our nation's children and young people. This, together with the considerable variation in child health teaching across UK medical schools, has led to increasing support for a national undergraduate curriculum for child health. This study aimed to establish clinicians' views on what the core components of an undergraduate child health curriculum should be.

Methods This study comprised three rounds. During Round 1, a range of clinicians involved in child health were asked what should be included in the child health curriculum. They included paediatricians, general practitioners, paediatric and general practice trainees, specialist nurses and medical students. All suggestions were treated equally and collated into a single list of key knowledge, skills and attitudes. In Round 2, participants ranked each of the suggestsions using a Likert scale (1-5). The mean, median and interquartile range for each time was calculated. In
Round 3, these pooled results were shared with participants, who were then invited to re-rank the items, using the Delphi methodology.

Results 80 people contributed to Round 1 within the allocated timeframe. Every UK medical school was represented. 56/80 (70\%) participants voted on the collated suggestions in Round 2. 48/56 (86\%) voted again for Round 3. Items scoring highly (mean $>4$ ) included knowledge of normal development and growth, recognition and initial management of the sick child and prescribing. Knowledge of global health outcomes and NHS structures for child health had a mean of $<3$. There was a wide range of opinions about whether the curriculum should include more generic items with relevance to child health such as performing a literature search to answer a clinical question and quality improvement.

Conclusions This study identifies core knowledge, skills and attitudes in child health deemed essential for all medical students. These components will form the basis for the national undergraduate curriculum in child health. The items were generated by a wide range of clinicians, academics and students and involved all UK medical schools, helping to maximise the curriculum's utility.

\section{G177 DO THE NEW FORMATIVE WORK BASED PLACED ASSESSMENTS IMPROVE EDUCATIONAL IMPACT?}

H Race, D James, C Fertleman. London Deanery, London, UK

\subsection{6/archdischild-2015-308599.172}

Aim To compare trainer and trainee experience when using the new Safeguarding Case Based Discussion (CbD) and Discussion of Correspondence (DoC) work place based assessments in comparison with the previous assessments.

Methods A collaborative trainee led group designed new formative work based place assessments that were launched by the $\mathrm{RCPCH}$ in September 2013. The aim of these reforms was a shift toward formative assessment, focusing on feedback and the removal of the more summative scoring system, with hypothesised improvement in their educational impact. An online survey was sent to all college tutors and London Deanery trainees to evaluate their experience of the new safeguarding $\mathrm{CbD}$ and DoC.

Results Responses from 161 trainees were evenly distributed throughout the training years. The majority of safeguarding CbDs took 15-20 min to perform. Trainees reported that $68 \%$ were filled out in person with the trainer, whereas college tutors reported 94\% were filled out with the trainee present. The most common barriers encountered when performing a safeguarding $\mathrm{CbD}$ were inadequate time or a neonatal rather than general paediatrics placement. $70 \%$ of trainees and $90 \%$ of tutors felt the new $\mathrm{CbD}$ better assessed the trainee's knowledge, application and clinical skills. $52 \%$ of trainees and $81 \%$ of tutors felt it stimulated learning more than the old style assessment. $64 \%$ of trainees and $87 \%$ of tutors felt learning objectives were clearer. Generally, a specific safeguarding CbD was seen as a useful tool.

On average, DoC took 5-10 min to complete. The majority of trainees and trainers found no barriers to completing a DoC. The majority of trainees did not feel that DoC stimulated their learning more than the old style Sheffield Assessment Instrument for Letters, however $76 \%$ of trainers felt it did allow better assessment of written correspondence.

Conclusion The new formative $\mathrm{CbD}$ assessment appears to improve the educational impact from both a trainer and trainee 
perspective. However, only the trainers not the trainees felt that the new DoC improved educational impact. The main barrier reported to completing both types of assessment was trainer and trainee time.

\section{G178 ABSTRACT WITHDRAWN}

\section{G179 IMPROVING LEADERSHIP AND MANAGEMENT SKILLS IN JUNIOR DOCTORS APPROACHING REGISTRAR LEVEL THROUGH A TRANSITION TO LEADERSHIP COURSE}

1,2LAC Menzies, ${ }^{2,3} \mathrm{SJ}$ Smith, ${ }^{4} \mathrm{~J}$ Moreiras, ${ }^{2,4} \mathrm{CR}$ Fertleman. ${ }^{1}$ Paediatric Department, Barnet General Hospital, London, UK; ${ }^{2}$ Assessment Subgroup, London Specialty School of Paediatrics, London, UK; ${ }^{3}$ Paediatric Department, St Mary's Hospital, London, UK; ${ }^{4}$ Paediatric Department, Whittington Hospital, London, UK

\subsection{6/archdischild-2015-308599.173}

Aims/Background Leadership and management skills are increasingly recognised as fundamental aspects of doctors' clinical practice and drive high-quality, safe healthcare services for patients. However, availability of specific leadership training is limited for junior doctors, with national bodies including the GMC, calling for increased availability of relevant training. We aimed to evaluate the need for and educational impact of a leadership course for paediatric trainees approaching registrar level.

Methods We ran a three day course for thirty paediatric ST3s, entitled 'Transition to Leadership', consisting of two training days in ST3 (SHO) and a third day after trainees had progressed to ST4 (registrar). The course incorporated the NHS Leadership
2014 cohort: Did the course change how you feel about starting as a Registrar?

Yes: $96 \%$ of attendees $(n=26)$

\section{Reasons Why?}

- How to communicate with consultant: feel empowered, know when to do so

- Practical advice on safeguarding, consent and end of life scenarios

- Tips, tools and strategies to cope with challenges/uncertainties

- Feel more confident

- Less anxious, calmer from sharing fears, knowing others felt the same

- Know how to lead the team effectively

- Feel excited/enthusiastic about taking on a new challenge

Reassuring: what the role involves and where to go for support

Reassured about the expectations i.e. not that of an ST8 but of an ST4

Less of an unknown fear

Know how to prepare before starting ST4 and areas to focus on

\section{Abstract G179 Figure 1}

Academy 'Health Leadership Model' and covered areas such as delegation, negotiation, supporting junior trainees and leading at night. In addition, key updates were included on safeguarding, consent and end-of-life care. We collected evaluation data from attendees at three time points: prior to the course, after day two, and after transition to ST4.

Results Paediatric ST3s felt unprepared for the transition to registrar, frequently citing concerns directly related to leadership and management capabilities. Following the course, trainees reported increased competence consistently across eight aspects of leadership and management. Perceived competence in two control aspects not covered on the course was unchanged, indicating a specific effect on leadership skills. Paired t tests demonstrated a significant increase in competence ranking seven of the

Abstract G179 Table 1 Comparing competence rankings before and after the transition to leadership course

\begin{tabular}{|c|c|c|c|c|c|}
\hline Rated Domain & $\begin{array}{l}\text { Pre Course* } \\
(n=30)\end{array}$ & $\begin{array}{c}\text { Post Day } \\
2^{*} \\
(n=26)\end{array}$ & $\begin{array}{c}\text { Post Day } \\
3^{*} \\
(n=13)\end{array}$ & $\begin{array}{l}\text { Mean } \\
\text { Difference in } \\
\text { competence } \\
\text { rating }\end{array}$ & $\begin{array}{l}\text { Paired sample } \\
\text { analysis }(n=24)^{* *}\end{array}$ \\
\hline \multicolumn{6}{|c|}{ Leadership, Management and Communication Domains } \\
\hline Knowing when to call my consultant & $2.9(0.61)$ & $3.5(0.51)$ & $3.5(0.66)$ & +1.6 & $T_{23}=-5.13, P<0.001$ \\
\hline Leading during a resuscitation & $2.2(0.63)$ & $2.5(0.58)$ & $3.0(0.58)$ & +0.8 & $T_{2 y}=-2.30, P=0.03$ \\
\hline Managing conflict & $2.5(0.51)$ & $2.9(0.53)$ & $3.2(0.43)$ & +0.7 & $T_{z}=-2.58, P=0.02$ \\
\hline $\begin{array}{l}\text { Managing cases with safeguarding } \\
\text { concerns }\end{array}$ & $2.3(0.60)$ & $3.2(0.59)$ & $3.2(0.44)$ & +0.9 & $T_{2:}=-5.17, P<0.001$ \\
\hline $\begin{array}{l}\text { Leading on difficult cases regarding } \\
\text { consent }\end{array}$ & $2.2(0.63)$ & $3.0(0.66)$ & $3.1(0.64)$ & +0.9 & $T_{2 y}=-4.70, P<0.001$ \\
\hline $\begin{array}{l}\text { Managing when a child dies on the ward } \\
\text { overnight }\end{array}$ & $1.7(0.52)$ & $2.9(0.69)$ & $3.1(0.86)$ & +1.4 & $T_{2 y}=-6.23, P<0.001$ \\
\hline $\begin{array}{l}\text { Leading and managing a team on a day } \\
\text { to day basis }\end{array}$ & $2.7(0.60)$ & $2.9(0.52)$ & $3.4(0.51)$ & +0.7 & $T_{2 g}=-2.01, P=0.06$ \\
\hline $\begin{array}{l}\text { Making mistakes and coping with } \\
\text { increased responsibility and } \\
\text { accountability }\end{array}$ & $2.2(0.73)$ & $2.7(0.62)$ & $3.3(0.63)$ & +1.1 & $T_{2 y}=-2.77, P=0.01$ \\
\hline \multicolumn{6}{|c|}{ Control Domains } \\
\hline Treating common neonatal problems & $2.9(0.55)$ & $2.9(0.43)$ & $3.0(0.41)$ & +0.1 & $T_{2 y}=-0.57, P=0.57$ \\
\hline Treating common paediatric problems & $3.0(0.41)$ & $2.9(0.39)$ & $3.0(0.41)$ & +0.0 & $T_{2:}=0.57, P=0.57$ \\
\hline
\end{tabular}

-Values shown indicate mean competence ranking across all trainees providing feedback at each stage with standard deviation in parentheses

- Paired sample T test for 24 trainees who attended both Day 1 and Day 2 of the course and completed pre course and post Day 2 feedback forms providing information allowing linking of their feedback forms 